\title{
Are Real Interest Rates of EU Accession Countries Characterized by Non-Linear Convergence?
}

\author{
Mark J. Holmes (Corresponding author) \\ Department of Economics, University of Waikato \\ Private Bag 3105, Hamilton 3240, New Zealand \\ Tel: 64-7-838-4454Ｅ-mail: holmesmj@waikato.ac.nz \\ Ping Wang \\ Birmingham Business School \\ University House, Birmingham, UK \\ Tel: 44-121-414-6675Ｅ-mail: wangpz@adf.bham.ac.uk
}

\begin{abstract}
In this study, we concurrently test for nonlinearity (threshold) effects and non-stationarity (unit roots) in real interest rate differentials. Using data for the ten accession countries that joined the EU in 2004, we find evidence of strong nonlinear effects. Long-run real interest rate parity has held for some of the sample, but subject to two different stationary regimes. Other countries are characterized with partial unit root behaviour insofar as differentials switch between alternative regimes of stationary and non-stationary behaviour.
\end{abstract}

Keywords: Real interest parity, Unit roots, Asymmetric adjustment. 


\section{Introduction}

Whether or not real interest rates have a tendency towards long-run equalisation across countries is an important issue for a number of reasons. Real interest rates play a key role in influencing real activity through saving and investment behaviour. For an open economy, confirmation or rejection of real interest parity (RIP) provides an indication of whether countries are financially integrated or autonomous. However, RIP can be viewed as a more general indicator of macroeconomic integration or convergence being associated with the attainment of purchasing power parity (PPP). In addition to this, RIP is a key working assumption in various models of exchange rate determination. The empirical studies on the validity of the RIP can be traced back to early studies such as Frenkel (1976), Mussa (1976), Frankel (1979), Mishkin (1984) and Cumby and Obstfeld (1984) followed by more recent investigations, such as Cavaglia (1992), MacDonald and Taylor (1989), Fraser and Taylor (1990), Edison and Pauls (1993), Moosa and Bhatti (1996), Fountas and Wu (1999) and others. While these studies employ a variety of significant methodological advances, the empirical literature provides at best mixed evidence regarding the validity of RIP.

In this paper, we investigate long-run RIP for ten European countries that accomplished entry to the European Union (EU) in May 2004. Such a study is warranted for a number of reasons. While many of these countries hold aspirations towards full membership of European Economic and Monetary Union (EMU), the preconditions require that various nominal and real convergence criteria are met. An investigation of RIP provides an additional perspective on the extent of real convergence and may be of help in assessing the readiness of each country to move towards EMU. It is possible however, that convergence may be present with regard to outside rather than within the Euro area. In considering convergence within the EU, Germany is usually taken as the benchmark real interest rate where Germany has been described as fulfilling an "anchor" role in the Exchange Rate Mechanism (ERM). (Note 1) In this study we allow for the possibility of convergence taking place with respect to a base outside the Euro area and employ the U.S. as an alternative benchmark against which convergence is measured.

In conducting this investigation, we test for stationarity of real interest rate differentials (RIRDs). Rather than adopt and rely on the familiar linear-based approaches to unit root testing such as augmented Dickey-Fuller (ADF) tests, we utilize a group of more powerful unit-root tests advocated by Perron (1997) and Caner and Hansen (2001) that take structural changes into account. In particular, the advantage of the Caner and Hansen (2001) method is that we are able to simultaneously test for the existence of asymmetries and unit roots in the behaviour of real RIRDs. Existing studies of RIP tend to compute a single test statistic for testing non-stationarity across the entire study period making no distinction between regime-dependent behavioural characteristics. This standard approach can lead to a bias towards accepting the non-stationary null thereby rejecting RIP, or give a false impression of the speed of adjustment towards long-run equilibrium because there is no distinction between alternative regimes. The approaches used in this paper allow the autoregressive parameter to switch according to regime change, and give insights into stationary or non-stationary behaviour that might characterize each case. 
In a recent study, Ferreira and Leon-Ledesma (2007) apply this approach to a group of emerging and developed countries and test for long-run RIP. They rely on using the U.S. as the reference large economy for the calculation of the RIRDs of five emerging economies: Argentina, Brazil, Chile, Mexico and Turkey; and five developed countries: France, Germany, Italy, Spain and the UK. For the emerging markets group, the half-lives of deviations from RIP are found to average 5.5 months but are shorter if the possibility of structural breaks is allowed for. Furthermore, the pattern of adjustment is found to be asymmetric insofar as RIRDs tend to behave differently depending on whether they are above or below a certain threshold. Indeed, for the chosen emerging markets used in this study, the adjustment is quicker when RIRDs grow fast. In contrast to Ferreira and Leon-Ledesma (2007), we focus on a sample comprising EU accession countries where we consider both Germany and the U.S. as alternative base real interest rates.

The remainder of the paper is structured as follows. In the following section, we discuss the theoretical background, methodology and relevant empirical literature on RIP. The third and fourth sections discuss the data and results from the group of unit root tests. Our data are monthly cover the study period 1993-2006. Our findings show that many RIRDs are characterised by asymmetries insofar as the behaviour of the RIRDs in each regime is significantly different. We find that for some countries, long-run RIP holds, but subject to two stationary regimes, whereas other countries are characterized with partial unit root behaviour suggesting that RIRDs switch between stationary and non-stationary regimes. The final section concludes.

\section{Theoretical Background and Literature Review}

RIP is the condition where real rates of return on identical assets are equalized across countries. In the two-country modelling of the relationship between domestic and foreign interest rates, perfectly substitutable bonds denominated in the home and foreign currencies are related according to the UIP relationship.

$$
\Delta S_{t+1}^{e}=i_{t}-i_{t}^{*}
$$

where $\Delta S_{t+1}^{e}$ is the expected change in the exchange rate measured as the domestic price of

foreign currency while the variables $i_{t}$ and $i_{i}^{*}$ stand respectively, for the domestic and foreign nominal interest rates.

Further assuming that the relationship between the two open economies is also characterized by the PPP linkage, the expected change in the exchange rate, conditional on current information, will depend on the relative rates of expected price inflation. The ex ante relative PPP condition suggests that the exchange rate responds to offset spreads in expected inflation across countries

$$
\Delta \pi_{t+1}^{e}-\Delta \pi_{t+1}^{* e}=\Delta S_{t+1}^{e}
$$


where $\Delta \pi^{e}$ refers to the expected rate of inflation, with $\pi$ expressed as the change in the natural logarithm of the price level.

When expectations about the exchange rate are reflective of the UIP and PPP relationships, the joint set of equations (1) and (2) can be used to imply

$$
\begin{gathered}
i_{t}-i_{t}^{*}=\Delta \pi_{t+1}^{e}-\Delta \pi_{t+1}^{* e} \\
i_{t}-\Delta \pi_{t+1}^{e}=i_{t}^{*}-\Delta \pi_{t+1}^{* e}
\end{gathered}
$$

Assuming that nominal interest rates satisfy Fisher parity relationship $r_{t}=i_{t}-\Delta \pi_{t+1}^{e}$ and $r_{t}^{*}=i_{t}^{*}-\Delta \pi_{t+1}^{* e}$ leads to the real interest parity relationship

$$
r_{t}=r_{t}^{*}
$$

It is clear that real interest parity jointly relates ex ante real interest rates to UIP and PPP conditions under Fisher parity relationship. The equalization of real interest rates in equation (4) requires that exchange rates and nominal interest rates are responsive to changes in expected inflation. Thus, if ex ante real interest differentials

$$
y_{t}=r_{t}-r_{t}^{*}
$$

are characterized by mean-reversion, RIP holds as a long-term equilibrium condition. The dynamics of real interest differentials is a function of the magnitude of departures from UIP expressed in equation (1) and the extent of relative forecasting errors, which cause deviations from PPP as expressed in equation (2).

Suppose $y_{t}$ is generated by the autoregressive process $y_{t}=a_{0}+a_{1} y_{t-1}+v_{t}$. Following a transformation, the usual test for linear adjustment towards RIP is based assessing the unit root properties of $y_{t}$ through the OLS estimation of Augmented Dickey Fuller (ADF) regressions such as

$$
\Delta y_{t}=a_{0}+\rho y_{t-1}+\sum_{i=1}^{p} \alpha_{i} \Delta y_{t-i}+\varepsilon_{t}
$$

where $v_{t}$ is a white noise residual and $\rho=\left(a_{1}-1\right)$. Here we find that $-2<\rho<0$ (consistent with $\left|a_{1}\right|<1$ ) indicates stationarity of the RIRD and long-run RIP. If so, $a_{0} \neq 0$ indicates that the RIRD series converges to a mean that is different from zero. 
The validity of the RIP relationship has been assessed using various econometric approaches and provides conflicting empirical evidence. Early attempts in studies such as Mishkin (1984) and Cumby and Mishkin (1986) use OLS regressions and find evidence against a long-run relationship. In later studies, the methodology for investigating RIP has included unit root testing [Meese and Rogoff (1988), Edison and Pauls (1993), among others] and cointegration testing with the allied concept of error correction modelling [Goodwin and Grennes, (1994), Moosa and Bhatti (1996), among others]. In the majority of cases, these studies find evidence against RIP. More recently, a variety of significant methodological advances have been employed in testing for RIP. For example, using panel data unit root testing, Holmes (2002) and Wu and Chen (1998) provide evidence in support of RIP. Kim (2006) applies the iterative seemingly unrelated regression $\mathrm{ADF}$ test and reports the evidence in support of the mean-reverting property of RIRDs in terms of traded goods. Recent studies of interest rate convergence involving the new EU member states include Kutan and Yigit (2004) who analyze both nominal and real interest rate differentials. They consider the post-1993 period and adopt a number of recent panel unit root testing approaches. Their results indicate limited degrees of nominal and real economic convergence. Kutan and Yigit (2005), on the other hand, employ the seemingly unrelated regression methodology in an analysis of nominal interest differentials concluding that the degree of nominal convergence is idiosyncratic.

An interesting line of research has recently developed that addresses the possibility of asymmetric or nonlinear dynamics of realignments towards RIP. For example, early work by Cavaglia (1992) notes the changing patterns in the behaviour of real interest differentials over time by utilising Kalman filtering techniques, while Fountas and Wu (1999) work within a cointegration approach that allows for structural breaks in the series and find evidence in favour of RIP in EU member countries. Pippenger and Goering (1993) and others argue that the presence of threshold nonlinearities reduces the power of standard unit root and cointegration tests. Indeed, Michael et al. (1997) show that cointegration or unit root tests may be biased when the linear alternative neglects nonlinearity of smooth transition autoregressive (STAR) type models. There is evidence from studies based on threshold autoregression models that within some neutral bands of transaction costs, the likelihood of adjustment towards equilibrium is rather low. The evidence from STAR models is also suggestive of a series of thresholds straddling the equilibrium conditions so that arbitrage opportunities increase with larger deviations from parity against a background of transaction costs. There is also a growing literature based on Markov-regime switching models. For instance, there is evidence from Dahlquist and Gray (2000) that the speed of adjustment of nominal interest rates in the European monetary system is stronger during periods of high interest rates and high volatility. Using a Markov-switching ADF test, Holmes and Wang (2008) find that the EU 2004 accession countries mostly adjust towards long-run RIP insofar as adjustment is characterised by regime switching between two stationary regimes, or between a stationary and non-stationary regime.

With this growing amount of statistical evidence, in addition to the specific feature of these new EU member countries, it seems appropriate to investigate the time-series properties RIRDs taking into account the possibility of regime shifts and asymmetries in adjustments 


\section{Al Macrothink}

Research in Applied Economics

ISSN 1948-5433

2009, Vol. 1, No. 1: E13

towards long-run equilibrium. The possibility of nonlinear dynamics is particularly relevant given that these countries have transformed from formal centrally planned economies towards market economies and are currently engaged in an on-going process of closer economic integration with the rest of the EU.

\section{Data}

The data used in this study consists of monthly observations on three month deposit rates and annualized inflation rates estimated from the consumer price indices for the ten European countries that joined the EU on the $1^{\text {st }}$ May 2004. The countries are Cyprus, Czech Republic, Estonia, Hungary, Latvia, Lithuania, Malta, Poland, Slovakia and Slovenia. The RIRDs are defined with respect to Germany and the United States. All data are retrieved from International Financial Statistics database where data availability dictates different start dates for each country. These are January 1991 for Cyprus, Hungary, Malta and Poland; January 1993 for the Czech Republic and Slovakia; February 1993 for Estonia; July 1993 for Latvia; February 1992 for Lithuania and December 1991 for Slovenia. In all cases, the study period finishes at December 2006 except for Lithuania which ends in January 2004. (Note 2) Since the end of the study period, Cyprus, Malta, Slovakia and Slovenia have proceeded towards EMU.

\section{Empirical Results}

\subsection{Unit root tests}

The first stage of the empirical investigation is to test whether the RIRDs with respect to the U.S. and Germany contain a unit root. This is initially done through the implementation of standard linear-based ADF unit root testing. (Note 3) Table 1 reports the results for twenty real interest rate differentials based on the exclusion of a deterministic trend. At the 5\% significance level, the non-stationary null is rejected in the cases of the Lithuania, Poland and Slovakia differentials with respect to Germany, whereas the null is rejected with respect to the U.S. more frequently, namely in the cases of Cyprus, Latvia, Lithuania, Poland Slovenia and Slovakia. In all other cases, the non-stationary null cannot be rejected leading us to initially conclude that evidence in favour of long-run RIP is limited. Indeed, these results suggest that convergence is actually strongest with respect to the U.S. rather than Germany. 
Table 1. ADF unit root tests on real interest rate differentials

\begin{tabular}{|c|c|c|c|c|}
\hline \multirow[t]{2}{*}{ Country } & \multicolumn{2}{|l|}{ Germany } & \multicolumn{2}{|l|}{ U.S. } \\
\hline & $\mathrm{ADF}$ & lags & $\mathrm{ADF}$ & lags \\
\hline Cyprus & $-2.808^{*}$ & 0 & $-4.731 * * *$ & 0 \\
\hline Czech Republic & -2.427 & 1 & -2.457 & 2 \\
\hline Estonia & $-2.748 *$ & 2 & $-2.581^{*}$ & 3 \\
\hline Hungary & -2.280 & 1 & -2.451 & 1 \\
\hline Latvia & $-2.784 *$ & 12 & $-4.029 * * *$ & 12 \\
\hline Lithuania & $-10.029 * * *$ & 14 & $-6.607 * * *$ & 17 \\
\hline Malta & $-2.616^{*}$ & 0 & -2.187 & 12 \\
\hline Poland & $-3.419 * *$ & 0 & $-3.471 * * *$ & 0 \\
\hline Slovenia & $-2.655^{*}$ & 20 & $-3.107 * *$ & 20 \\
\hline Slovakia & $-3.217^{* *}$ & 0 & $-3.127 * *$ & 0 \\
\hline
\end{tabular}

Notes: These are ADF unit root tests conducted on real interest rate differentials (excluding a deterministic trend). The lag length is based on BIC critical values. The critical values at $1 \%, 5 \%, 10 \%$ significance levels (without a trend) are $-3.46,-2.88$ and -2.57 respectively.

When using the standard ADF unit-root tests, a number of problems arise. First, it is well known that the power of these tests tends to be low, leading to over-acceptance of the null of a unit root. This problem is magnified for small samples because a stationary series could be drifting away from its long-run equilibrium level in the short run. A second potential problem arises from the possible existence of structural breaks in the series given the specific feature of these transition economies. When there are structural breaks, the standard unit root tests are biased towards the non-rejection of a unit root (Perron, 1989). This issue is addressed in the following section.

\subsection{Perron (1997) structural break tests}

If asymmetry is present in RIRDs, linear unit-root tests will suffer from a loss of power. Regarding the existence of structural breaks, Perron (1997) develops a procedure to test for unit roots that endogenously search for structural breaks in the series(Note 4). This model can be represented as 


$$
y_{t}=a_{0}+\theta D U_{t}+\lambda D\left(T_{b}\right)_{t}+\rho_{1} y_{t-1}+\sum_{i=1}^{p} \beta_{i} \Delta y_{t-i}+\varepsilon_{t}
$$

where $T_{b}$ denotes the break date; $D U_{t}=1\left(t>T_{b}\right)$ and $D\left(T_{b}\right)_{t}=1\left(t=T_{b}+1\right)$. The test is performed using the t-ratio for the null hypothesis that $\rho_{1}=1$.

Table 2 reports the findings from the application of Perron's (1997) test. Each test assumes that the series contain an innovational outlier with a change in the intercept as shown in equation (7). At the 5 percent level, we can reject the unit root hypothesis for the Estonia, Latvia, Lithuania and Slovenia differentials with respect to Germany. With respect to the U.S. pairs, we are able to reject the unit root null for Hungary, Latvia, Lithuania, Slovenia and Slovakia. The date breaks are mostly around 1994-1995 and 1998-1999 and reflect two sources of structural change: the transition period from command to market economy in the early to mid-1990s, and on-going integration into the EU from the late 1990s onwards. These transition and integration processes have characterised by a series reforms spanning a wide range of economic and political adjustments, including market liberalization, stabilization policies, entry regulations and privatization, state enterprise restructuring, tax reforms, bankruptcy reforms and banking reforms (Foster and Stehrer, 2007).

Table 2. Perron (1997) test

\begin{tabular}{|l|l|l|l|l|l|l|}
\hline & \multicolumn{5}{l}{ Germany } & \multicolumn{5}{l}{$l$} \\
& lags & Break date & t-ratio & lags & Break date & t-ratio \\
\hline Cyprus & 12 & $1993: 09$ & -3.32 & 12 & $2002: 10$ & -4.51 \\
\hline Czech Rep. & 12 & $1999: 11$ & -4.43 & 12 & $1996: 12$ & -3.55 \\
\hline Estonia & 9 & $1998: 12$ & $-5.18^{* *}$ & 3 & $1998: 10$ & -4.62 \\
\hline Hungary & 8 & $1999: 02$ & $-4.53^{*}$ & 10 & $1994: 04$ & $-5.35^{* *}$ \\
\hline Latvia & 12 & $1999: 07$ & $-6.02^{* * *}$ & 12 & $2001: 03$ & $-6.58^{* * *}$ \\
\hline Lithuania & 11 & $1994: 07$ & $-15.70^{* * *}$ & 11 & $1994: 07$ & $-15.61^{* * *}$ \\
\hline Malta & 12 & $1997: 01$ & -4.33 & 12 & $2001: 07$ & -4.24 \\
\hline Poland & 10 & $1993: 01$ & -4.77 & 10 & $2000: 07$ & $-5.02^{*}$ \\
\hline Slovenia & 9 & $1995: 01$ & $-6.80^{* * *}$ & 9 & $1994: 11$ & $-6.07^{* * *}$ \\
\hline Slovakia & 9 & $1996: 12$ & -4.40 & 9 & $1999: 07$ & $-6.06^{* * *}$ \\
\hline
\end{tabular}




\subsection{Structural break with asymmetric adjustment}

The assumption of Perron's (1997) test is that the series under consideration follows a linear path or a linear path with a break. In other words, the test employs an alternative hypothesis based on symmetric mean-reverting behaviour of RIRDs to positive and negative shocks. However, recent developments in the theory of imperfect capital markets and information suggest that the behaviour of RIRDs may be asymmetric because risk perceptions may vary with changes in interest rates themselves. Indeed, theoretical models in which market segmentation arises from various transaction costs introduces non-linearities into the adjustment of real exchange rates- a result which has also implications for real interest convergence. Studies such as Sarantis (1999), Taylor and Peel (2000) and Nakagawa (2002) provide evidence that the realignment process of exchange rates is characterized by nonlinearities. Caner and Hansen (2001) further relax the linearity assumption by proposing a test that simultaneously allows for nonlinearity (threshold effects) and non-stationary (unit roots) using the following threshold autoregressive (TAR) with two regimes. Suppose

$$
\Delta y_{t}=I_{t}\left[\theta_{1} y_{t-1}+\sum_{i=1}^{p} \beta_{i} \Delta y_{t-i}\right]+\left(1-I_{t}\right)\left[\theta_{2} y_{t-1}+\sum_{i=1}^{p} \beta_{i} \Delta y_{t-i}\right]+e_{t}
$$

where $I_{t}$ is the indicator function,

$$
I_{t}=\left\{\begin{array}{l}
1 \quad \text { if } z_{t-1}<\lambda \\
0 \quad \text { if } z_{t-1} \geq \lambda
\end{array}\right.
$$

and where $\lambda$ is a threshold, $e_{t}$ is an iid error term, and the variable $z_{t}$ is any stationary variable that would determine the change of regime. Following Caner and Hansen (2001), we can set $z_{t}=y_{t}-y_{t-m}$ which implies that RIRDs behave differently depending on whether past changes in the series have been higher or lower than a certain threshold $\lambda$. The lag length $m$ for the changes in RIRDs is data-determined as is the search for the optimal threshold $\lambda$.(Note 5) Finally, the parameter vectors $\theta_{1}$ and $\theta_{2}$ can be partitioned as

$$
\theta_{1}=\left(\begin{array}{l}
\mu_{1} \\
\rho_{1}
\end{array}\right), \quad \theta_{2}=\left(\begin{array}{l}
\mu_{2} \\
\rho_{2}
\end{array}\right)
$$

where $\mu_{i}$ is an intercept and $\rho_{i}$ is the autoregressive parameter with $i=1,2$ for the two regimes, respectively.

In order to test for whether there is any statistical evidence to reject the linear AR model in favour of a threshold model, Caner and Hansen (2001) advocate testing the null $H_{0}: \theta_{1}=\theta_{2}$ based on the OLS estimation of equation (8), making use of the Wald statistic $\left(W_{T}\right)$ proposed 
in Caner and Hansen (2001). Since the parameter $\rho_{1}$ and $\rho_{2}$ control the "stationarity" of the process $y_{t}$ in equation (8), the unit root hypothesis involves testing for the null hypothesis $H_{0}: \rho_{1}=\rho_{2}=0$. There are two possible alternatives:

$$
\begin{gathered}
H_{1}: \rho_{1}<0 \text { and } \rho_{2}<0 \text {, and } \\
H_{2}:\left\{\begin{array}{l}
\rho_{1}<0 \text { and } \rho_{2}=0 \\
\text { or } \\
\rho_{1}=0 \text { and } \rho_{2}<0
\end{array}\right.
\end{gathered}
$$

The first alternative corresponds to the stationary case, and if $\mathrm{H}_{2}$ holds, the series exhibits partial unit root behaviour, i.e. the process $y_{t}$ will behave like a unit root process in one regime, but will perform like a stationary process in the other. Caner and Hansen (2001) develop a group of statistics to test for $H_{0}$ against $H_{1}$ and $H_{2}$. The first statistic tests the null $H_{0}$ against the unrestricted alternative $\rho_{1} \neq 0$ or $\rho_{2} \neq 0$, using the Wald statistic $R_{2 t}=t_{1}^{2}+t_{2}^{2}$, where $t_{1}$ and $t_{2}$ are the $t$-ratios for $\rho_{1}$ and $\rho_{2}$, respectively. However, $R_{2 t}$ is a two-sided Wald statistic, whereas the authors recommend testing $H_{0}$ using a one-sided Wald statistic. Therefore, Caner and Hansen (2001) define $R_{1 t}=t_{1}^{2} I_{\rho_{1}<0}+t_{2}^{2} I_{\rho_{2}<0}$ where rejection of the null supports rejection of the unit root hypothesis in favour of stationarity characterised by a structural break and asymmetric adjustment. In order to discriminate between the two alternatives in $H_{2}$, Caner and Hansen (2001) recommend looking at the $t$-ratios of $\rho_{1}$ and $\rho_{2}$ obtained in equation (8). (Note 6)

The results from applying Caner and Hansen (2001) tests are presented in Table 3. We first look at whether there exists statistical evidence to reject the linear AR model in favour of a threshold model by inspecting the Wald test $W_{T}$. The most important feature is that the null of no asymmetry is rejected at the $5 \%$ significance level in sixteen out of twenty pairs. A further three rejections involving Cyprus and Malta occur at the $10 \%$ significance level. Overall, these results suggest that the adjustment towards RIP does exhibit nonlinear patterns. 
Table 3. Threshold and unit root tests

a. Vis-à-vis Germany

\begin{tabular}{|l|l|l|l|l|l|l|l|l|l|l|}
\hline Country & \multicolumn{9}{|l}{ Parameter Estimates } & \multicolumn{3}{l}{$\begin{array}{l}\text { Threshold and Unit Root Tests } \\
\text { (p-values) }\end{array}$} \\
\hline & $\lambda$ & $\mathrm{m}$ & $T_{1}$ & $T_{2}$ & $\rho_{1}$ & $\rho_{2}$ & $W_{T}$ & $R_{1 T}$ & $t_{1}$ & $t_{2}$ \\
\hline Cyprus & 0.64 & 3 & 0.55 & 0.45 & -0.076 & -0.042 & 0.077 & 0.036 & 0.774 & 0.005 \\
\hline Czech Rep. & -2.39 & 6 & 0.14 & 0.86 & -0.062 & -0.064 & 0.000 & 0.185 & 0.658 & 0.064 \\
\hline Estonia & 4.82 & 6 & 0.81 & 0.19 & -0.045 & -0.054 & 0.000 & 0.346 & 0.223 & 0.452 \\
\hline Hungary & -3.85 & 11 & 0.16 & 0.84 & -0.175 & -0.006 & 0.000 & 0.000 & 0.000 & 0.229 \\
\hline Latvia & -2.37 & 3 & 0.23 & 0.77 & -0.733 & -0.087 & 0.000 & 0.243 & 0.173 & 0.385 \\
\hline Lithuania & -4.74 & 2 & 0.14 & 0.86 & 0.220 & -0.137 & 0.000 & 0.003 & 0.005 & 0.021 \\
\hline Malta & -1.60 & 12 & 0.16 & 0.84 & 0.051 & -0.061 & 0.055 & 0.410 & 0.958 & 0.200 \\
\hline Poland & 3.71 & 3 & 0.80 & 0.20 & -0.115 & 0.014 & 0.000 & 0.464 & 0.424 & 0.338 \\
\hline Slovenia & 1.83 & 9 & 0.73 & 0.27 & -0.372 & -0.224 & 0.000 & 0.002 & 0.001 & 0.213 \\
\hline Slovakia & -1.53 & 5 & 0.32 & 0.68 & -0.291 & -0.066 & 0.026 & 0.060 & 0.039 & 0.234 \\
\hline
\end{tabular}


Table 3. Threshold and unit root tests (continued)

b. Vis-à-vis U.S.

\begin{tabular}{|c|c|c|c|c|c|c|c|c|c|c|}
\hline \multirow[b]{2}{*}{ Country } & \multicolumn{6}{|c|}{ Estimates } & \multicolumn{4}{|c|}{$\begin{array}{l}\text { Threshold and unit root tests } \\
\text { (p-values) }\end{array}$} \\
\hline & $\lambda$ & $\mathrm{m}$ & $T_{1}$ & $T_{2}$ & $\rho_{1}$ & $\rho_{2}$ & $W_{T}$ & $R_{1 T}$ & $t_{1}$ & $t_{2}$ \\
\hline Cyprus & -0.21 & 10 & 0.41 & 0.59 & -0.238 & -0.091 & 0.166 & 0.074 & 0.040 & 0.370 \\
\hline Czech Rep. & -2.91 & 10 & 0.14 & 0.86 & -0.040 & -0.020 & 0.007 & 0.832 & 0.790 & 0.530 \\
\hline Estonia & 4.88 & 7 & 0.82 & 0.18 & -0.041 & 0.063 & 0.000 & 0.384 & 0.157 & 0.958 \\
\hline Hungary & -4.33 & 8 & 0.16 & 0.84 & -0.181 & -0.041 & 0.003 & 0.476 & 0.513 & 0.311 \\
\hline Latvia & -3.73 & 3 & 0.15 & 0.85 & -0.441 & -0.262 & 0.000 & 0.112 & 0.677 & 0.047 \\
\hline Lithuania & -5.74 & 4 & 0.14 & 0.86 & 0.138 & -0.116 & 0.000 & 0.000 & 0.004 & 0.006 \\
\hline Malta & -0.03 & 7 & 0.53 & 0.47 & -0.042 & -0.177 & 0.098 & 0.366 & 0.250 & 0.370 \\
\hline Poland & -0.26 & 3 & 0.47 & 0.53 & 0.033 & -0.199 & 0.000 & 0.072 & 0.282 & 0.045 \\
\hline Slovenia & -0.40 & 7 & 0.46 & 0.54 & -0.333 & -0.252 & 0.000 & 0.116 & 0.144 & 0.158 \\
\hline Slovakia & -3.33 & 2 & 0.22 & 0.78 & 0.013 & -0.162 & 0.004 & 0.126 & 0.721 & 0.041 \\
\hline
\end{tabular}

Note: $\lambda$ is the threshold; $m$ is the selected lag order used to specify the threshold variable $Z_{t}$;

$T_{1}$ and $T_{2}$ are the percentages of the observations lie in regimes 1 and 2, respectively. $\rho_{1}$ and $\rho_{2}$ are the coefficients on the lagged level of the RIRD in each regimes; $W_{T}$ is the threshold (nonlinearity) test; $R_{1 T}$ is the unit root test in the nonlinear model; $t_{1}$ and $t_{2}$ are the unit root test for each of the threshold regimes. $p$-values for the threshold and unit root tests were obtained from 1,000 bootstraps replications of Caner and Hansen (2001).

To determine whether the regimes are non-stationary or not, we may consider the unit root statistics are $R_{1 T}\left(R_{2 T}\right), t_{1}$ and $t_{2}$. At the selected delay parameter $m$, we observe that the unit root null is rejected at the 5\% significance level for 5 out of 10 pairs with respect to Germany: Cyprus, Hungary, Lithuania, Slovenia and Slovakia. For these cases, this evidence supports the hypothesis of a high degree of market integration consistent with financial 
liberalization and the emergence of global capital markets. While Slovenia and Slovakia have proceeded to joining the Euro area, it is clear that evidence of convergence extends to non-Euro members as well. By the same token, the absence of long-run RIP with respect to Germany that we detect includes Malta which has adopted the single currency, and Estonia and Latvia who have the status of a relatively high liberalization of capital movements among the accession countries and a longer track record of removed exchange controls where a currency board or fixed peg regime has been maintained. This finding sends a note a caution on the mixed degree of real and financial integration that recent and prospective members of EMU might actually have with existing members. In contrast to Ferreira and Leon-Ledesma (2007), we find that long-run RIP with respect to the U.S. is much less extensive in our sample than the five different emerging countries they consider. With only three rejections of the unit root null (Cyprus, Lithuania and Poland), we find evidence of RIP with respect to the U.S. is even weaker than is the case with Germany.

Table 3 reports the parameter estimates, i.e. estimated threshold $(\lambda)$, the lag of the change in RIRDs for the determination of the threshold $(m)$, the percentage of the total observations lies in regime $1\left(T_{1}\right)$ and regime $2\left(T_{2}\right)$, and the estimate of $\rho_{i}$ as shown in equation (8) for both regimes. The point estimates of the threshold $\lambda$ ranges from -4.74 to 4.82 , which splits the regression function into two regimes depending on whether the variation in RIRDs between the previous period and period $m$ (variable $z_{t-1}$ ) lies above or below the threshold value $\lambda$. For example, in the case of Cyprus-Germany where $\lambda=0.64$ and $m=3$, the first regime is where $z_{t-1}<0.64$, which occurs when RIRD has fallen, remained constant, or has risen by less than 0.64 points over a three-month period. Within this regime, the RIRD behaviour is like a unit root process. The second regime occurs where $z_{t-1}>0.64$, that is, RIRD has risen by more than 0.64 points in three-month period. Within this regime, the RIRD is mean reverting, with the speed of adjustment towards long-run RIP being 16 months. (Note 7)

The extent to which real interest rates are involved in long-run equilibrium relationship is a useful guideline for assessing the degree of real convergence. In this study, we have conducted a formal analysis of real interest parity involving ten new EU member states against the U.S. and Germany. In contrast to the existing literature, this paper has brought into focus the possibility that evidence on long-run real interest parity is susceptible to variations in the persistence of regimes over time, given the specific feature of these countries that have gone through a severe transition process towards a market economy from the early 1990s onward and, currently, on-going process of economic integration within the EU. It is possible indeed that the dynamics of RIRDs are more accurately described by regimes where local adjustment towards RIP does or does not occur. The failure to account for such non-linearities, in terms of switches between regimes of stationary and non-stationary behaviour may increase the likelihood of evidence against long-run parity by introducing a bias towards longer half-lives of deviations from real interest parity. Based on a group of 
unit root tests that address these issues, we find some evidence of nonlinear behaviour in these real interest rate differentials towards RIP, reflecting the transition process and economic integration embodied in these economies. There is, however, variability in the extent of convergence across the new EU members: some show switching between two stationary regimes with different speeds of adjustment towards RIP, while others shift between stationary and non-stationary regimes. Our findings suggest that RIP is less prevalent among the EU accession countries that joined in 2004 than is the case for other emerging economies from around the world.

\section{Acknowledgements}

We are grateful for helpful comments received from participants at the 2008 INFINITI Conference on International Finance held at Trinity College, Dublin with particular thanks to Andreas Hanhardt and Brian Lucey. We are also grateful for constructive comments received from the Editor and an anonymous referee. The usual disclaimer applies.

\section{References}

Caner, M., \& Hansen, B.E. (2001). Threshold autoregressions with a unit root. Econometrica, 69, pp. 1555-1596.

Cavaglia, S. (1992). The persistence of real interest differentials: a Kalman filtering approach. Journal of Monetary Economics, 29, pp. 429-443.

Cumby, R., \& Mishkin, F. (1986). The international linkage of real interest rates: the European-U.S. connection. Journal of International Money and Finance, 5, pp. 5-23.

Cumby, R., \& Obstfeld, M. (1984). International interest rate and price level linkages under flexible exchange rates: a review of recent evidence. In: J. Bilson \& R.C. Marston, (Eds), Exchange Rate Theory and Practice (pp. 121-152). Chicago: University of Chicago Press.

Dahlquist, M., \& Gray, S.F. (2000). Regime-switching and interest rates in the European monetary system. Journal of International Economics, 50, pp. 399-419.

Edison, H.J., \& Pauls, B.D. (1993). A re-assessment of the relationship between real exchange rates and real interest rates: 1974-1990. Journal of Monetary Economics, 31, pp. 165-187.

Elliott, G., Rothenberg T.J., \& Stock, J.H. (1996). Efficient tests for an autoregressive unit root. Econometrica, 64, pp. 813-836.

Ferreira, A.L., \& Leon-Ledesma, M.A. (2007). Does the real interest parity hypothesis hold? evidence for developed and emerging markets. Journal of International Money and Finance, 26, pp. 364-382.

Foster, N., \& Stehrer, R. (2007). Modeling transformation in CEECs using smooth transitions. Journal of Comparative Economics, 35, 57-86.

Fountas, S., \& Wu, J. (1999). Testing for real interest rate convergence in European countries. Scottish Journal of Political Economy, 46, pp. 158-174. 


\section{Mll Macrothink}

Frankel, J. (1979). On the mark: a theory of floating exchange rates based on real interest differentials. American Economic Review, 69, pp. 610-622.

Fraser, P., \& Taylor, M.P. (1990). Some efficient tests of international real interest parity. Applied Economics, 22, pp. 1083-92.

Frenkel, J., (1976). A monetary approach to the exchange rate: doctrinal aspects of empirical evidence. Scandinavian Journal of Economics, 78, pp. 200-224.

Goodwin, B., \& Grennes, T. (1994). Real interest rate equalization and the integration of international financial markets. Journal of International Money and Finance, 13, pp. 107-124.

Hafer, R.W., \& Kutan, A.M. (1994). A long-run view of German dominance and the degree of policy convergence in the EMS. Economic Inquiry, 22, pp. 684-695.

Herz, B., \& Roger, W. (1992). The EMS is a greater Deutschmark area. European Economic Review, 32, pp. 1413-1425.

Holmes, M.J., \& Wang, P. (2008). Real convergence and regime-switching among EU accession countries. South-Eastern Europe Journal of Economics, 1, pp. 9-27.

Holmes, M.J., (2002). Does long-run real interest parity hold among EU countries? some new panel data evidence. Quarterly Review of Economics and Finance, 42, pp. 733-746.

Karfakis, C., \& Moschos, D. (1990). Interest rate linkages within the European Monetary System: a time series analysis. Journal of Money, Credit, and Banking, 22, pp. 388-394.

Kim, J. (2006). Reconsidering real interest parity for traded and nontraded goods. Review of International Economics, 14, pp. 306-315.

Kutan, A. M., \& Yigit, T.M. (2004). Nominal and real stochastic convergence of transition economies. Journal of Comparative Economics, 32, pp. 23-36.

Kutan, A. M., \& Yigit, T.M. (2005). Real and nominal stochastic convergence: are the new EU members ready to join the Euro zone? Journal of Comparative Economics, 33, pp. 387-400.

Kwiatkowski, D., Phillips, P. C. B., Schmidt, P., \& Shin, Y. (1992). Testing the null hypothesis of stationarity against the alternative of a unit root. Journal of Econometrics, 1, pp. 159-178.

MacDonald, R., and Taylor, M.P. (1989). Interest rate parity: some new evidence. Bulletin of Economic Research, 41, pp. 255-274.

Meese, R., \& Rogoff, K. (1988). Was it real? the exchange rate-interest differential relation over the modern floating-rate period. The Journal of Finance, 43, pp. 933-948.

Michael P., Nobay R., \& Peel, D. (1997). Transactions costs and nonlinear adjustment in real exchange rates: an empirical investigation. Journal of Political Economy, 105, pp. 862-879. 
Mishkin, F. (1984). Are real interest rates equal across countries: an empirical investigation of international parity conditions, Journal of Finance, 39, pp. 1345-1357.

Moosa, I., \& Bhatti, R. (1996). Some evidence on mean reversion in ex ante real interest rates. Scottish Journal of Political Economy, 43, pp. 177-191.

Mussa, M. (1976. The exchange rate, balance of payments, and monetary and fiscal policy under a regime of controlled floating. Scandinavian Journal of Economics, 78, pp. 229 -248.

Nakagawa, H. (2002). Real exchange rates and real interest rate differentials: implications of nonlinear adjustment in real exchange rates. Journal of Monetary Economics, 49, pp. 629-649.

Ng, S., \& Perron, P. (2001). Lag length selection and the construction of unit root tests with good size and power. Econometrica, 69, pp. 1519-1554.

Perron, P. (1989). The great crash, the oil price shock, and the unit root hypothesis, Econometrica, 57, pp. 1361-1401.

Perron, P. (1997). Further evidence on breaking trend functions in macroeconomic variables. Journal of Econometrics, 80, pp. 355-385.

Pippenger, M.K., \& Goering, G.E. (1993). A note on the empirical power of unit root tests under threshold processes. Oxford Bulletin of Economics and Statistics, 55, pp. 473-481.

Sarantis, N. (1999). Modeling nonlinearities in real effective exchange rates. Journal of International Money and Finance, 18, pp. 27-54.

Taylor, M.P., \& Peel, D.A. (2000). Nonlinear adjustment, long-run equilibrium and exchange rate fundamentals. Journal of International Money and Finance, 19, pp. 33-53.

Van Poeck, A., \& Van Gompel, J. (1994). Dominant interest and inflation differentials within the EMS: a comment. European Economic Review, 38, pp. 1661-1663.

Wu, J-L., \& Chen, S-L. (1998). A re-examination of real interest rate parity. Canadian Journal of Economics, 31, pp. 837-851.

\section{Notes}

Note 1. For evidence in favour of the German dominance in the Exchange Rate Mechanism (ERM) see Herz and Roger (1992), Karfakis and Moschos (1990), Hafer and Kutan (1994). Stronger evidence of German leadership is offered by van Poeck and van Gompel (1994).

Note 2. Line I64 for the consumer price index and line I60L for deposit rate (the exception is the U.S. where the corresponding line is I60LC). The use of the bank deposit interest rate data is dictated by the data availability across our large sample of countries. Treasury bill and interbank rates are not available on a consistent basis across the sample period.

Note 3. We also conducted KPSS testing based on Kwiatkowski et al. (1992) as well as Elliot et al. (1996) and Ng and Perron (2001) unit root tests that offer higher power and less size distortion relative to the more familiar ADF test. These additional tests were unable to provide 
stronger evidence of RIP.

Note 4. Perron (1997) suggests two methods in the search for structural breaks in the series. First, the break date is chosen where the t-ratio attached to the null hypothesis of a unit root is smallest among all possible break points. Second, the break point corresponds to the maximum absolute value of the t-ratio on the parameter associated with the change in the intercept. To save the space, we only report the result from the first method. The results from the second method are available upon request.

Note 5. $m$ is selected endogenously, that is, the least squares estimate of $m$ is the value that minimises the residual variance, which is equivalent to selecting $m$ as the value that maximizes $W_{T}$.

Note 6. Given that the asymptotic null distribution of the asymmetry test is non-standard, Caner and Hansen (2001) develop an asymptotic theory for the distribution of this unit root test and recommend the use of bootstrapping for finite samples. As the distribution of the test statistic will depend on whether or not a threshold effect exists, $p$-values obtained through the bootstrap are not unique.

Note 7. The speed of adjustment toward RIP following a random shock is calculated as the half-life at which the effect of the shock is reduced by 50 percent; i.e. the half-life is approximated by $\ln (0.5) / \ln (1+\hat{\rho})$ where $\hat{\rho}$ is the estimated autoregressive coefficient. 